\title{
Achieving functionality through modular build-up: structure and size selection of serine oligopeptidases
}

\author{
$\underline{\text { Anna KISS-SZEMÁN }}^{1}$, Veronika HARMAT ${ }^{1,2}$, Dóra K. MENYHÁRD ${ }^{2}$ \\ ${ }^{1}$ Eötvös Loránd University, Institute of Chemistry, Laboratory of Structural Chemistry and Biology, \\ ${ }^{2}$ MTA-ELTE Protein Modelling Group, \\ address: Pázmány Péter sétány 1/A, H-1117, Budapest, Hungary \\ tel.:(+36-1) 372-2500/6547, fax: (+36-1) 372-2592 \\ web: prot.chem.elte.hu \\ e-mail: kszemananna@ chem.elte.hu
}

\begin{abstract}
keywords: oligopeptidase; oligopeptide hydrolysis; acylaminoacyl-peptidase; acylpeptide hydrolase; $\beta$ edge aggregation; substrate selection; multimerization; substrate access; self compartmentalization; conformation selection
\end{abstract}

\begin{abstract}
Enzymes of the prolyl oligopeptidase family ( $\mathrm{S} 9$ family) recognize their substrates not only by the specificity motif to be cleaved but also by size - they hydrolyze oligopeptides smaller than 30 amino acids. They belong to the serine-protease family, but differ from classical serine-proteases in size (80 $\mathrm{kDa}$ ), structure (two domains) and regulation system (size selection of substrates). This group of enzymes is an important target for drug design as they are linked to amnesia, schizophrenia, type 2 diabetes, trypanosomiasis, periodontitis and cell growth. By comparing the structure of various members of the family we show that the most important features contributing to selectivity and efficiency are: (i) whether the interactions weaving the two domains together play a role in stabilizing the catalytic triad and thus their absence may provide for its deactivation: these oligopeptidases can screen their substrates by opening up, and (ii) whether the interaction-prone $\beta$-edge of the hydrolase domain is accessible and thus can guide a multimerization process that creates shielded entrance or intricate inner channels for the sizebased selection of substrates. These cornerstones can be used to estimate the multimeric state and selection strategy of yet undetermined structures.
\end{abstract}

\section{Introduction}

In 2002 a new group of serine-proteases, the prolyl-oligopeptidase (POP) family (S9 family) was categorized as enzymes of $\alpha / \beta$-hydrolase fold hosting a regular serine protease active site. Their first description was based on the sequence homology of prolyl oligopeptidase (POP, also referred to as prolyl endopeptidase (PREP)), oligopeptidase B (OPB), dipeptidyl-peptidase IV (DPP4) and acylaminoacyl 
peptidase (AAP) (also called acylpeptide hydrolase (APEH)). The two major differences between the classic serine proteases (such as the chymotrypsin-like and subtilisin-like proteases) and these first identified members of the oligopeptidase family, was their size ( $80 \mathrm{kDa}$ as compared to that of $25-30 \mathrm{kDa}$ of trypsin and subtilisin) and their selectivity, which is restricted to oligopeptides smaller than 30 amino acids [1]

Oligopeptidases share a common modular structure, being composed of a hydrolase and a propeller domain (Figure 1). This also leads to similar tertiary structures even though their sequence homology is basically restricted to the hydrolase domain containing the Ser-His-Asp amino acids of the catalytic triad. The core of the hydrolase domain comprises of the C-terminal segment of the sequence but it usually also contains the very first few to dozens of residues of the N-terminus, forming loops or helix-loop-helix motifs attached to the surface of the hydrolase-core [2] (Figure 1).
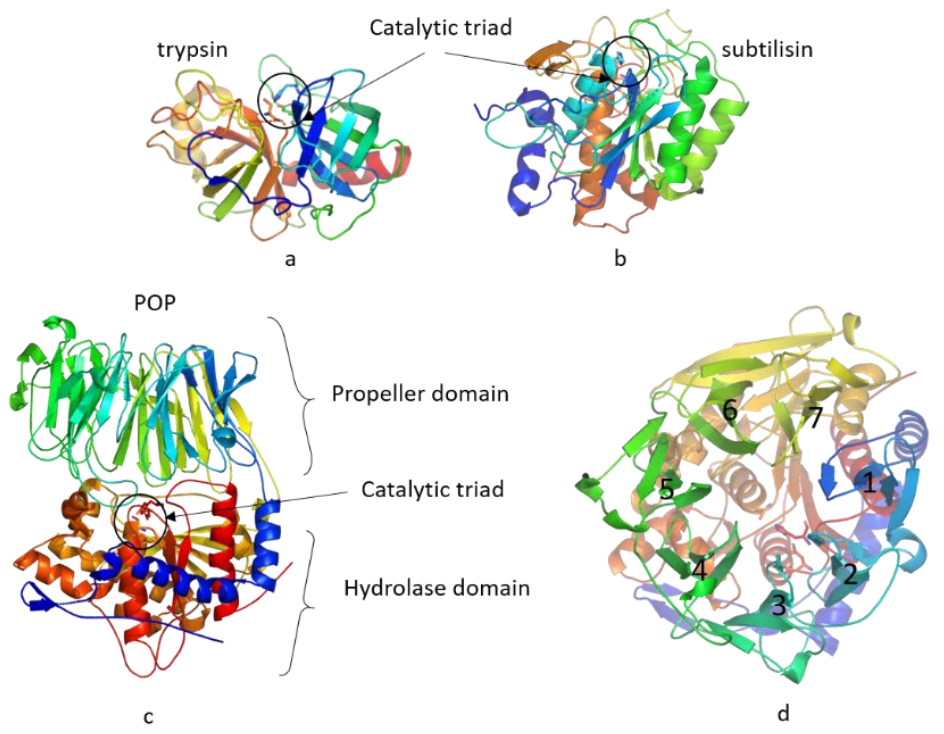

Figure 1 Comparison of the she structures of bovine trypsin subtilisin and prolyl oligopeptidase. The structures of the monomers are shown in a schematic representation. In case of trypsin (a; PDB: 1tgb) and subtilisin (b; PDB: 2sbt) the active site is solvent exposed and allows unhindered approach to the site of hydrolysis. c) The two domain structure of oligopeptidases is quite distinct amongst the serine-protease families. The large $\beta$-propeller of prolyl oligopeptidase (PDB: $1 \mathrm{~h} 2 \mathrm{w}$ ) domain serves as a shield to protect to "naked" active site. The hydrolase domain is composed of a short segment at the N-terminus (blue) and the C-terminal half of the sequence (in orange and red) d) the propeller domain (from above), with numbered blades

The highly variable propeller domain serves as a shield to protect the active site. POP [3], OPB [4] and AAP [5] propellers are 7-bladed, while DDP4 [6] has an 8-bladed propeller domain. The blades are 4stranded antiparallel $\beta$-sheets, arranged around a central channel, which is wide enough to allow the entrance of small, unstructured peptides to the spacious inter-domain cavity - the site of the catalytic hydrolysis. 
In this review we summarize the structural characteristics of oligopeptidases overviewing the structures available in the MEROPS database [7] (https://www.ebi.ac.uk/merops/cgi-bin/famsum?family=S9, accessed November 15, 2018) This peptidase database sorts the serine-dependent peptidases into four subfamilies (A-D) based on their sequence homology (especially characteristic motifs around the catalytic Ser), aminopeptidase activity and tertiary structure. POP, DPP4 and AAP are prototypes for S9A, S9B and S9C subfamilies. Glutamyl endopeptidase was recently assigned to the family, creating the S9D subfamily, however its structure is not solved yet. Additionally there is a group of enzymes belonging to this family as "not assigned", containing dipeptidyl peptidase homologues DPP6 and DPP10, puromycin hydrolase with same POP-like fold and acetylcholinesterase, carboxylesterase, lipase, serine carboxylpeptidase having alpha/beta/alpha sandwich fold, similar to proteins of the S10 family. By comparing the available structures our aim is to understand how the functionality of these proteins is architectured, focusing on protection against aggregation, substrate access and size-selectivity.

\section{Discussion}

\subsection{Physiological significance}

S9A subfamily - POP is an effector of cognitive processes, such as depression, schizophrenia, anorexia and bulimia nervosa [8-10]. Since numerous neuroactive peptides were shown to be substrates of POP it has been suggested to influence the processes of aging and neurodegeneration [11] and it became a therapeutic target for the treatment of cognitive and neurodegenerative disorders [12].

OPB is present in protozoan parasites, such as Trypanosoma cruzi that causes the Chagas disease in humans, and the African trypanosomes that are associated with sleeping disease [13, 14].

S9B subfamily - DPP4 is a cell surface serine protease that cleaves a dipeptide segment from peptides containing proline or alanine in the N-terminal penultimate position [15]. In 2006, DPP4 inhibitors were approved for the treatment of type 2 diabetes mellitus. This new class of antidiabetic agents - the "gliptins" available as sitagliptin, saxagliptin, vildagliptin, linagliptin, and alogliptin - enhance mealstimulated insulin secretion from pancreatic $\beta$-cells by sparing the hormone glucagon-like peptide-1 (GLP-1) and glucose-dependent insulinotropic peptide (GIP) from degradation initiated by DPP4 [1618]. DPP4 is also linked to diabetes associated microvascular side effects [19].

Similar to DPP4 is the fibroblast activation protein (FAP), which is overexpressed in epithelial cancers is thus connected to tumor growth, and metastasis [20]. DPP6 is a potassium channel accelerating factor (KAF) [21, 22]. DPP8, DPP9 and DPP10 play pathophysiological roles in cancer biology and immune response [23, 24]. They are also linked to inflammatory diseases and the immune system [25-27].

Prolyl tripeptidyl aminopeptidase (PTP) from Porphyromonas gingivalis was first identified [28] to release a tripeptide, X-X-Pro, from substrates possessing an N-terminal free amino group and a proline 
residue at the third position from the $\mathrm{N}$-terminus. This enzyme was also suggested to be a member of the POP-family. The Gram-negative anaerobe $P$. gingivalis is a major pathogen associated with adult periodontitis [29], [52] leading to tooth-loss, and certain cardiovascular [53] and kidney disorders [54], as well as rheumatoid arthritis [55].

S9C subfamily - AAP has been shown to be able to degrade multimeric forms of the amyloid-peptide present in the Alzheimer's brain [30]. It is also a key protein in the upstream regulation of the proteasome [31,32] affecting protein maturation and degradation processes [33-36], cell survival [37-39] and DNA-damage response [40]. Furthermore, a recent study indicates that the proteomic changes caused by inhibiting AAP result in significant increase in T-cell proliferation. This pro-proliferative effect of AAP inhibition is also supported by the fact, that AAP is deleted in certain cancers, where it has been proposed to serve as a potential tumor suppressor [41].

Lasso peptide isopeptidases (IsoPs) from Sphingopyxis alaskensis belong to the ribosomally synthetized and post-translationally modified peptide (RiPP) family and to the S9C subfamily of prolyloligopeptidases. They function as antimicrobials, enzyme inhibitors, and receptor antagonists [42].

S9D subfamily - Glutamyl endopeptidases (GSEs) hydrolyze peptide bonds formed by $\alpha$-carboxyl groups of Glu and Asp residues. Bacterial GSEs are related to chymotrypsin-like serine proteases [43,44]. The GSEs from pathogenic strains of Staphylococcus (known as V8 protease, Glu-C or SspA) and Enterococcus are important virulence factors [45-47] and are linked to staphylococcal scalded skin syndrome [48-51].

Peptidases not assigned to subfamily - Porphyromonas gingivalis acylpeptidyl-oligopeptidase (PgAOP) is a new member of the family which was shown to play a role in bacterial cell growth and pathogenicity $P g A O P$ functions by cleaving $\mathrm{N}$-acetylated di- and tripeptides form oligopeptide segments [56].

Puromycin hydrolase (PMH) also called Streptomyces morookaensis AAP (Sm AAP) was recently characterized as a POP-like enzyme that inactivates puromycin by hydrolysis of its amide bond. Puromycin (PM), one of the nucleoside antibiotics, inhibits the growth of prokaryotic and eukaryotic cells. It inhibits protein synthesis by substituting for aminoacyl t-RNA and serves as an acceptor for the nascent peptide chain of ribosome-bound peptidyl t-RNA [57,58].

There are further enzymes in this group without known structures or with solved structures lacking the characteristic propeller domain, which will not be discussed here.

\subsection{Multimer formation}


A curious aspect of oligopeptidases is the wide variety of multimerization states that they exist and function in. Streptomyces morookaensis AAP, certain forms of OPB and POP are monomeric [58-60], AAP from Aeropyrum pernix (ApAAP), DPP4, PTP from Porphyromonas gingivalis and OPB from other sources form dimers [61-65]. Sporosarcina psychrophyla AAP form dimers and tetramers, both catalytically active [66], the active form of PhAAP is a hexamer [67], while mammalian AAP is tetrameric $[68,69]$.

It was originally assumed that multimerization could have a structure-stabilization effect. However, the comparative molecular dynamics analysis of the monomer PhAAP (for which the functional protein is a hexamer) and the physiologically monomeric POP revealed that although both molecules show global relaxation in the solvated medium, both are stable as monomers [70-72]. In a previous work [73], we presented another plausible explanation for multimerization. There is an 8 membered $\beta$-sheet at the center of the hydrolase domain (Figure 2.) In all oligopeptidase structures so far determined, the catalytic His is located on a loop that connects the terminal $\beta$-strand of this central $\beta$-sheet and an $\alpha$-helix. Both are located at the surface of the core region of the hydrolase domain where this terminal strand serves as an ideal aggregation primer (,sticky $\beta$-edge”) [74]. The corresponding sequences form various oligopeptidases were all recognized by the WALTZ predictor [75] as having high probability for amyloid formation (Table 1). Thus we proposed that hiding this sticky $\beta$-edge might be an important factor in the association of the monomers into multimeric structures.

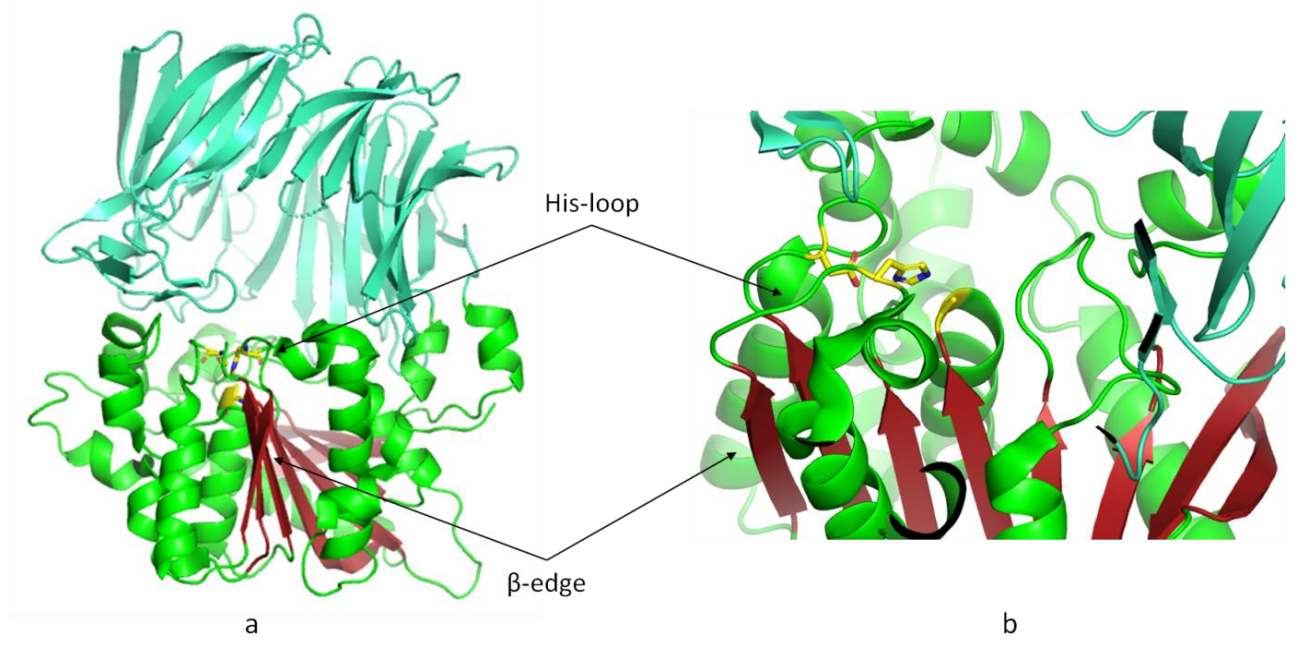

Figure 2 Structural elements of the hydrolase domain suggested to be important for multimer formation and regulating activity. a) The 8 stranded $\beta$-sheet (red) at the center of the hydrolase domain (green). The catalytic triad (yellow) is covered by the propeller domain (cyan). b) The catalytic His (yellow) is located on a loop that connects the terminal $\beta$-strand of this central $\beta$-sheet and an $\alpha$-helix. (Shown for PhAAP ;PDB: 4hxg.)

TABLE 1 Summarizing the sequences of the aggregation-prone outer $\beta$-strands (sticky edge) of the $\beta$-sheet forming the core of the hydrolase domain (column 3). The oligomeric state of the protease is related to the aggregation propensity of the sticky edge.

\begin{tabular}{|l|l|l|l|l|l|}
\hline Enzyme name & PDB & $\beta$-edge forming residues & Predicted & Oligomeric state in & Complex \\
\hline
\end{tabular}




\begin{tabular}{|c|c|c|c|c|c|}
\hline & ID & & $\begin{array}{l}\text { aggregation } \\
\text { propensity } \\
\text { of the } \beta- \\
\text { edge }\end{array}$ & $\begin{array}{l}\text { the functional form } \\
\text { of the protease }\end{array}$ & $\begin{array}{l}\text { Formation } \\
\text { Significance } \\
\text { Score(PISA) }\end{array}$ \\
\hline POP (human) & $1 \mathrm{~h} 2 \mathrm{w}$ & 668-NPLLIHVDTK-678 & 79.93 & monomer & 0.000 \\
\hline OPB (L. major) & $2 \mathrm{xe} 4$ & 685-NEILLNIDMES-695 & 94.01 & monomer & 0.000 \\
\hline OPB (T. brucei) & $4 b p 8$ & 671-NEVLLKMDLES-681 & 81.27 & dimer & 0.000 \\
\hline DPP4 (human) & $1 \mathrm{j} 2 \mathrm{e}$ & 729-DFQAMWYTDE-738 & 89.41 & dimer & 1.000 \\
\hline PTP & 2eep & 698-YPDYYVYPSH-708 & 80.47 & dimer & 0.561 \\
\hline AAP (A. pernix) & $304 \mathrm{~g}$ & 462-FKAGVAGASV-471 & 80.69 & dimer & 0.925 \\
\hline $\begin{array}{l}\text { AAP } \\
\text { horikoshii) }\end{array}$ & 4 hxe & 566-KEVYIAIFKK-575 & 93.98 & hexamer & 0.892 \\
\hline $\begin{array}{l}\text { AAP } \\
\text { psychrophyla) }\end{array}$ & $518 \mathrm{~s}$ & 560-RDVEYLVLED-569 & 79.93 & dimer/tetramer & 0.528 \\
\hline $\begin{array}{l}\text { IsoP } \\
\text { alaskensis })\end{array}$ & $5 \mathrm{jrk}$ & 653-VATQISYYPG-662 & 92.94 & dimer & 1.000 \\
\hline $\begin{array}{l}\text { PMH/AAP } \\
\text { (S. } \\
\text { morookaensis) }\end{array}$ & $3 a z o$ & 613-VPHAYLSFEG-622 & 87.63 & monomer & 0.011 \\
\hline $\begin{array}{l}\text { AOP } \\
\text { gingivalis })\end{array}$ & modell & 722-FEVPYMVKYN-731 & 92.17 & monomer/oligomer & no data \\
\hline AAP (human) & - & 696-PVRLLLYPKS-705 & 88.29 & tetramer & no data \\
\hline
\end{tabular}

${ }^{a}$ The scores for aggregation propensities predicted by WALTZ [75](http://waltz.switchlab.org, accessed November 15, 2018 (column 4), number being higher than 75 indicates that submitted sequence is prone to amyloid-type aggregation.

b PISA (Protein interfaces, surfaces and assemblies' service at the European Bioinformatics Institute, http://www.ebi.ac.uk/pdbe/prot_int/pistart.html, accessed November 15, 2018) [76] calculates intermolecular interactions of molecular interfaces in submitted structures. The Complex Formation Significance Score for the interaction (CSS) ranges from 0 to 1 as interface relevance to complex formation increases. Low CSS implies that the interface is not significant for complex formation and may be solely a result of crystal packing.)

This notion is supported by the fact, that in monomeric oligopeptidases as POP and OPB, the sticky $\beta$ strand is covered by a long N-terminal extension thus need no protection. In case of the also monomeric Streptomyces morookaensis AAP, instead of its $\mathrm{N}$-terminal segment, a short $\mathrm{C}$-terminal extension could be responsible for shielding the outer $\beta$-strand (Figure 3). 


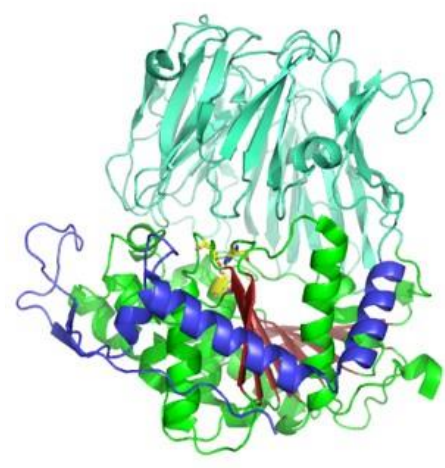

a

Figure 3 Two types vof structural elements shielding the sticky edge in monomeric oligopeptidases. In most known strucutres the $\mathrm{N}$-terminal helical extension covers the sticky edge () , while ..tructure of closed LmOPB (a; PDB: 2xe4)

The sticky-edge (red) in the hydrolase domain (green) is covered by an N-terminal extension (blue), catalytic triad (yellow), propeller domain (cyan) and C-terminal extension (black).

In dimer, tetramer and hexamer forming oligopeptidases such as ApAAP, DPP4, PTP and PhAAP, the unprotected sticky $\beta$-strands at the outermost surface of the monomers are hidden by their multimeric complex forms (Figure 4).
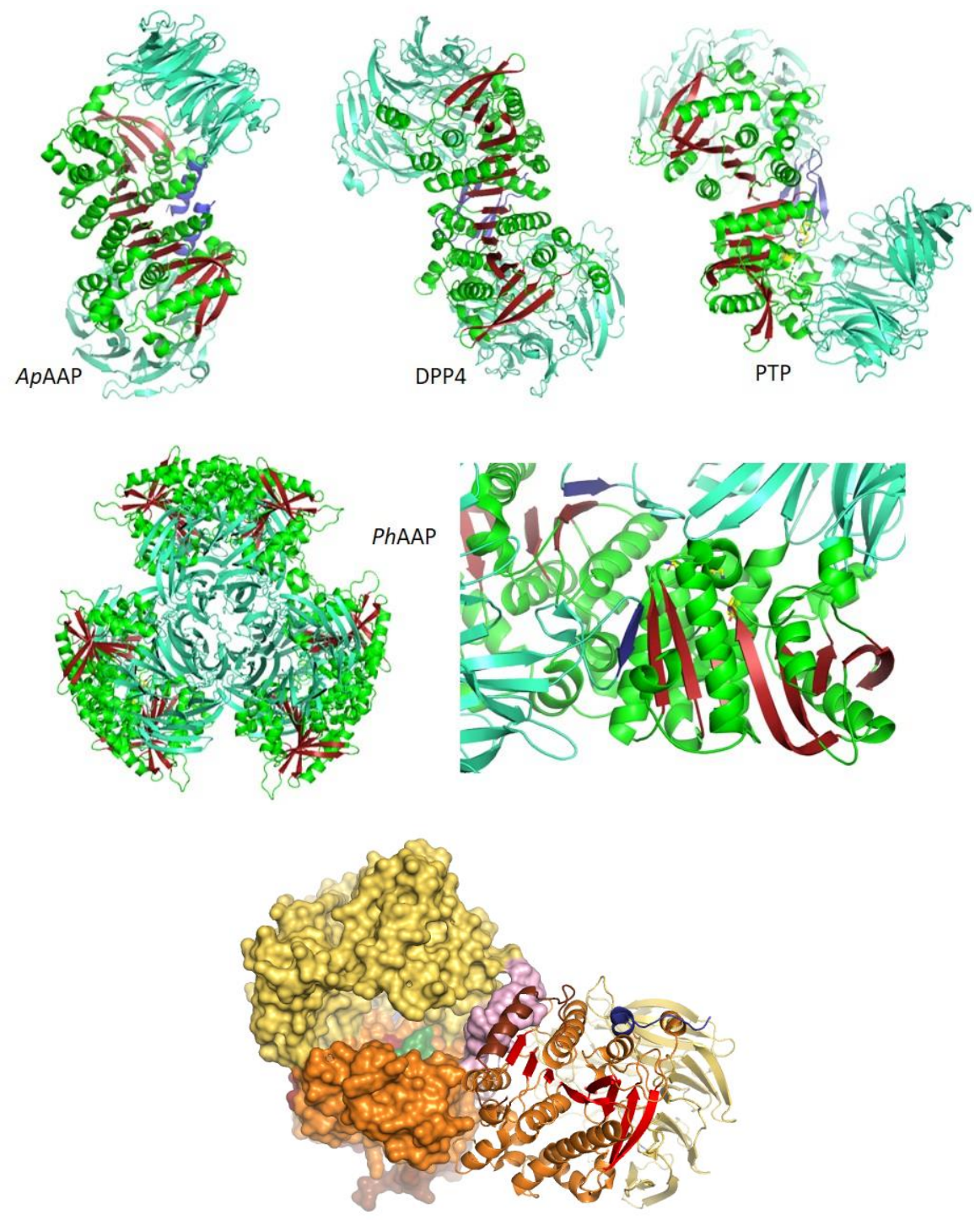
Figure 4 Structural elements shielding the sticky edge of the hydrolase domain in multimeric oligopeptidases. In dimeric structures of ApAAP (PDB: 3o4g), DPP4 (PDB: 1j2e) and PTP (PDB: 2eep) showing the two monomers (hydrolase domain in green, propeller domain in cyan) creating a 16-stranded large $\beta$-sheet (red). In the PhAAP (PDB: $4 \mathrm{hxg}$ ) hexamer the $\beta$-edge is covered by a loop extension of the propeller (blue) of a neighboring monomer. In the SpI-IsoP (PDB 5jrk) dimer the longer C-terminal extension helix (brown) is involved in dimer formation, along with the large insertion of blade 3 (pink) is covering the sticky $\beta$-edge of the neighboring monomer.

\subsection{Providing access to the active site}

The structure of oligopeptidases has to be optimal for two quite opposing goals: size selection via hiding the catalytic site from large, structured proteins, and effectivity by providing access to the active site. A hydrolase domain capped by a propeller can provide the required selectivity since the substrate entrance and product exit can only proceed through the narrow channel of the propeller. This channel on the other hand, can only accommodate completely unfolded peptides of no more than a dozen amino acids - which is hardly effective. Thus, some additional pathways to the site of hydrolysis must exist.

POP, OPB and ApAAP form the most compact monomers in the family. However, of all 3 it has been shown that via hinge movements, the monomers can open up [5, 63, 70, 73, 77,78]. The hinge between the two domains is created by a varying number of amino acids, from short ( 6 amino acids, POP) to quite long segments (20 amino acids, PhAAP) in two strands connecting the propeller domain to the hydrolase domain (Figure 5).
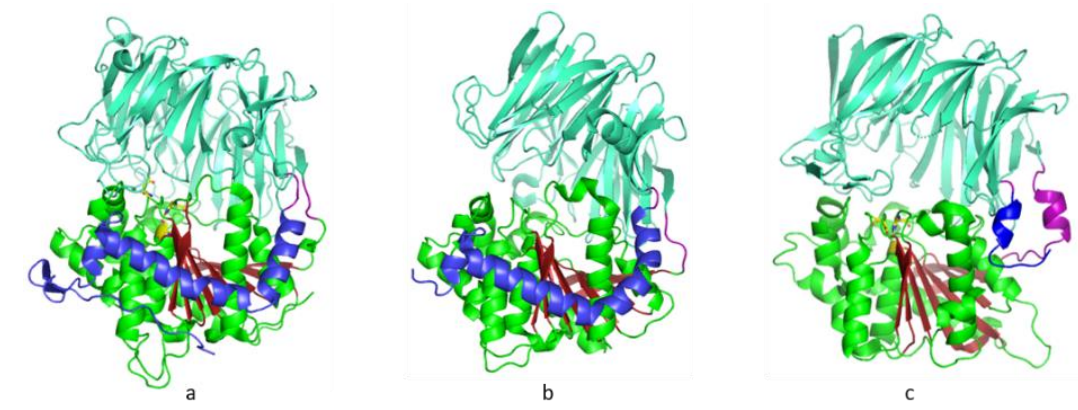

Figure 5 Hinge regions between the domains of open and closed structures. a) The closed and b) open structure of POP (PDB: $1 \mathrm{~h} 2 \mathrm{w}, 5 \mathrm{t} 88$ ) and c) the monomer of PhAAP (stabilized in the closed state by multimerization) with the large side-opening is shown. The hinge region is formed by a short segment following the helical N-terminal moiety (blue) and a segment of varying size between the two domains (magenta).

In case of DPP4, PTP, PhAAP and SpI-IsoP, on the other hand, a side entrance to the active cavity is permanently present already in the monomer form, created by shorter blades of the propeller domain (Figure 6). In DDP4 the side opening to the active site is generated by the kinked arrangement of blade 1 and 2 (PDB: 1j2e). In PTP blades 2 and 3 are shortened and bent, thus creating the quite large entrance on the side of the monomer (PDB: 2eep). In PhAAP it is also blade 2 that is shorter, and there is a long insertion in blade 3 stabilizing the structure with contacts to the neighboring monomer and hydrolase domains (PDB: 4hxe). 
In case of lasso-peptide peptidase SpI-IsoP, both gel-filtration experiments and its crystal structure (PDB: 5jrk) showed the active form of the enzyme to be dimeric. The formation of the dimer leads to covering the "naked" sticky edge and the catalytic pocket can be reached by a rather large and structured side entrance of the monomers, where the intact active site is located. A large side entrance is created by a propeller breaking insertion in blade 4, and its missing blade 5 (PDB: 5jrk) [42]. This is presumably important for the bulky lasso peptide substrate to approach the catalytic site. (Figure 6).

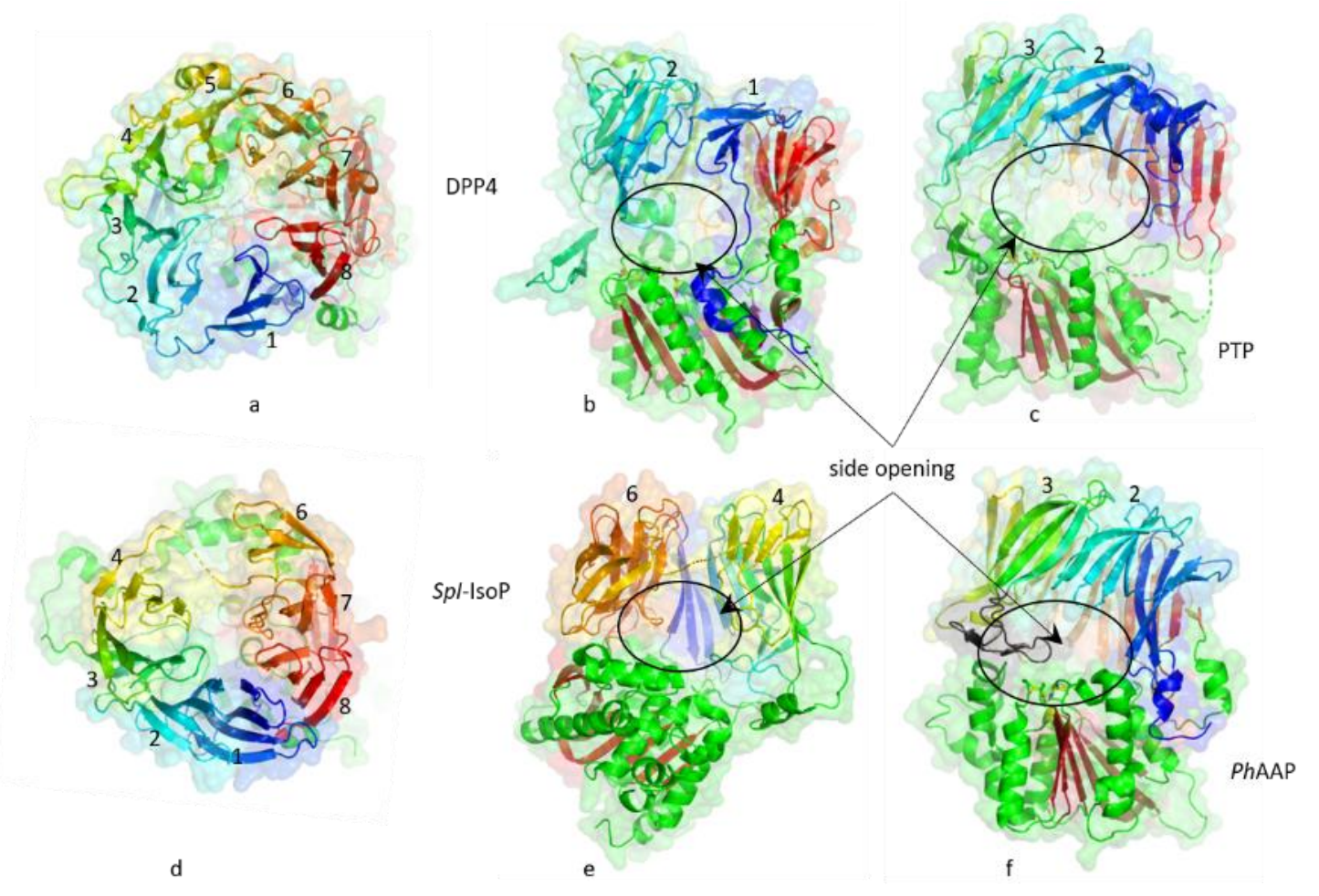

Figure 6 Rigid oligopeptidase structures create side-openings. a) The propeller domain (colored by sequence, blades numbered) of DPP4 from above with kinked blade1 (dark blue) and blade2 (light blue) creating b) side opening. In c) PTP and f) PhAAP shortened blades 2 and 3 create the large entrance (black circle) on the side of the monomer. In PhAAP a long extension of blade3 (black) can modulate the size of the opening due to its flexibility. $\mathrm{d}$ ) the propeller domain (colored by sequence, blades numbered) of SpI-IsoP from above with missing blade5 creating e) side opening.

An interesting further example with permanent entrance is Sporosarcina psychrophyla acylaminoacyl peptidase (SpAAP; PDB: 518s), a cold adapting enzyme with a 7-bladed propeller. SpAAP has both a side gate and an enlarged propeller channel suggested to compensate for the restricted flexibility of the domains in the cold environment by providing two possible direct routes to the active site [68].

Thus, considering the substrate access, all known oligopeptidase structures can be assigned to two distinct groups: structures that open up and have no side gates in their closed form, and rigid, multimeric enzymes with a widened propeller pore to provide for substrate access.

\subsection{Maintaining selectivity}


Thus, in the oligopeptidase family, the two strategies described above, guarantee the effective approach of substrates. Both of these, however, abolish the size-selectivity achieved by the two domain build-up. Therefore, both of these strategies must be paired with a process that provides for size-selection. For those oligopeptidases that are able to open and close, parting of the two domains disassembles the catalytic triad in the open structures. This means that the open form becomes a forager of possible substrates, however peptide bond cleavage will only take place if the enzyme is able to close upon them. This way, even if large, structured proteins reach the active site, they will not be hydrolyzed. Structures of both the open and closed forms have been determined for POP, OPB and ApAAP. In case of the open structure of Pyrococcus furiosus POP (PDB: 5t88) the loop holding the catalytic His is displaced (Ser-His distance increased from $2.9 \AA$ to $9.6 \AA$, measured at the $\mathrm{C} \alpha$-s, Figure 7). In another, recently solved, structure of the open form of POP (from Novosphingobium capsulatum POP (PDB: 1yr2, [78]) the complete His-loop is missing from the electron density, indicating its elevated flexibility. Similar structural effects can be seen in the open monomer of OPB from Trypanosoma brucei (PDB: 4bp8, [63]) and Galerina marginata (PDB: 5n4f, [79]) where the catalytic His was either removed from the triad (shifting by $11.2 \AA$ (measured at the $\mathrm{C} \alpha-\mathrm{s}$ ) or it was completely destabilized by the opening. In case of ApAAP (PDB: 3o4g) an activated open and a deactivated closed conformer was detected in the same crystal lattice forming a heterodimer. The His-loop was resolved in both forms, but in the open state the distance of the SerO $\gamma$ and HisNe2 increases from $3.1 \AA$ to $14.7 \AA$ (Figure 8, [73]). Thus, the opening of these oligopeptidases leads to inactivation by a significant distortion of the catalytic triad. This is possible because in these cases interdomain interactions contribute to the stabilization of the active site loops holding the catalytic His and Asp residues in the closed form - thus when the structure opens and these interactions are lost, the active site becomes disassembled.
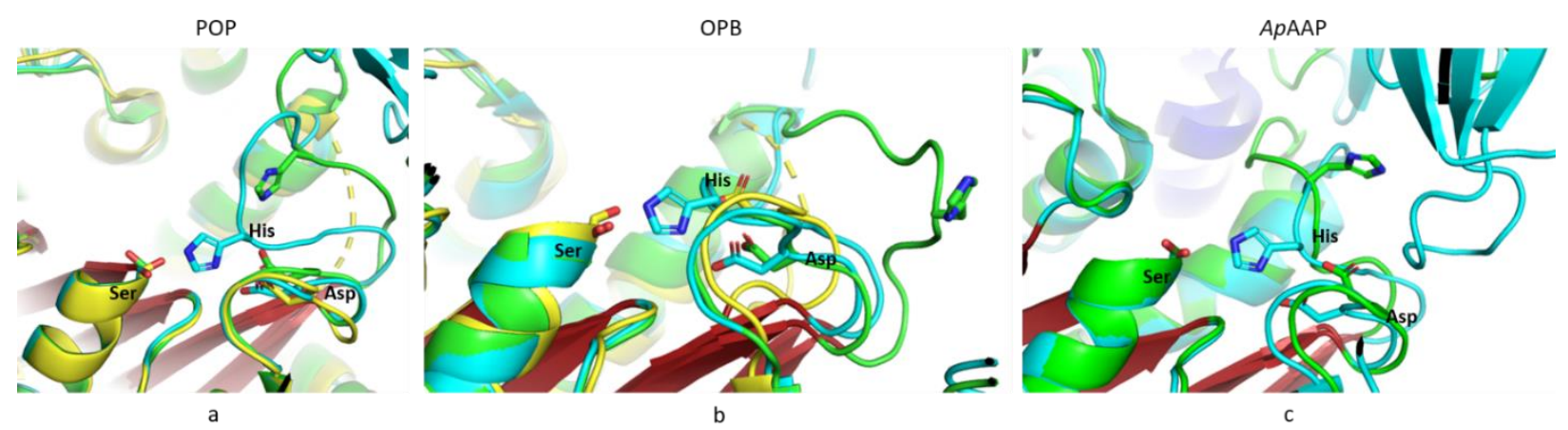

Figure 7 Comparison of the open and closed structures of POP, OPB and ApAAP shows the catalytic triad distortion via opening process.

a) closed (cyan), semi-open (green) and open (yellow) structures of human (PDB:1h2w), P. furiosus (PDB: 5t88) and N. capsulatum (PDB: 1yr2) POP. b) closed (cyan), semi-open (yellow) and open (green) structures of L. major (PDB: 2xe4), T.brucei (PDB: 4bp8) and G. marginata (PDB: 5n4f) OPB. c) closed (cyan) and open (green) structure of A. pernix AAP (PDB: 3o4g) occurring in same crystal lattice. 
Those oligopeptidases that form a permanent side entrance were all found to form multimers that either partially or fully hide these gateways. In the DPP4 dimer [62], N-terminal insertions from each monomer form an X-shaped cross, whereas the eight-pleated central $\beta$-sheets meet in a perpendicular orientation. This considerably restricts the accessibility of the entrance. In case of PhAAP hexamerization leads to a special quaternary structure encompassing a channel system with bottlenecks at the side openings of the monomers which face inward into the central cavity of the hexamer [71] (Figure 8). The PTP dimer is an interesting exception, as itsside entrance is wide open [REF].
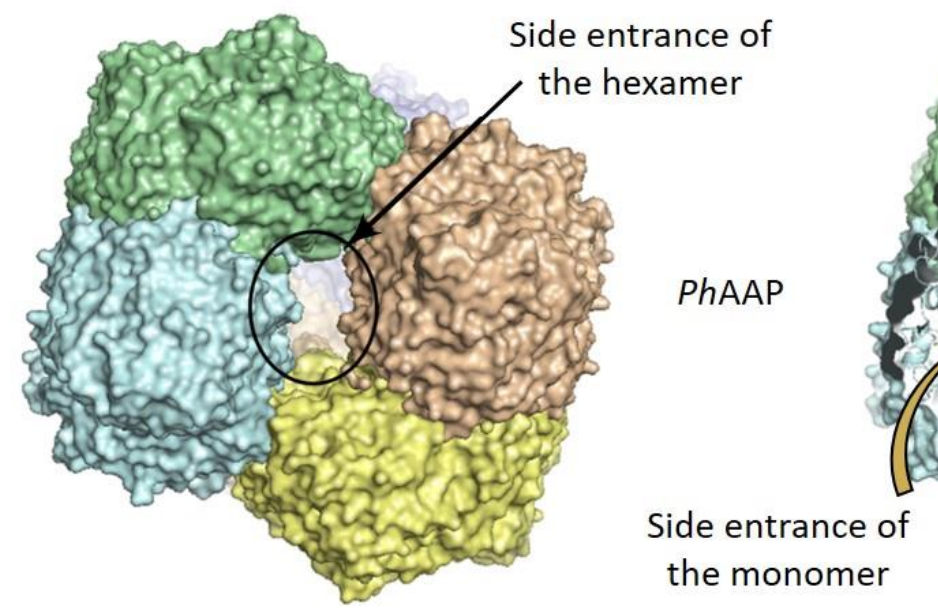

Figure 8 The hexameric structure of P. horikoshii AAP (4hxe). a) creating a channel system to control size selection of the substrates. The permanent openings of the monomers face inward the quaternary structure, while the catalytic triad is in active configuration. The molecular surface of the molecules are shown; left: side view of the hexamer; right: intersection of the hexamer in the same orientation.

\subsection{Functional oligopeptidases}

POP, we've seen, has a monomeric structure where the sticky $\beta$-edge is covered by the $\mathrm{N}$ terminal extension. It is a dynamic structure, capable of opening and closing. Its interdomain interactions stabilize the His-loop so its opening deactivates its catalytic triad. Therefore it is stable and functional in the monomeric form. OPB is quite similar: although it has been shown to dimerize, this is an association of idenpendetly functional monomers, and is not connected to its catalytic activity. ApAAP is also a dynamic oligopeptidase with a deactivated open form, but its critical $\beta$-edge is unprotected. Its functional form is thus a dimer where the $\beta$-strand of one monomer is covered by the corresponding strand of the other, in an antiparallel manner. Since this dimerization mode only connects the hydrolase domains, the interdomain flexibility of the monomer units is retained allowing the access of substrates by domain movement (Figure 9).

DPP4 and PTP have a permanent side entrance and an unprotected outermost $\beta$-stand, thus they form rigid dimers. Here substrate selection must be provided by the size of the side-opening, because the catalytic triad is stabilized in an active conformation. In case of $\boldsymbol{P h} \mathbf{A A P}$ that also forms a side-gate and 
contains a freely approachable $\beta$-edge, the loop insertion of blade 3 of one monomer lines up to the sticky $\beta$-strand of the other and forms a ninth, antiparallel strand of the central $\beta$-sheet forming a dimer. These dimers are further organized into the hexamer with a complex channel system providing a quite effective mean of the size selection. SpAAP forms dimers, but in this structure the $\beta$-edge is not covered. Size selection of subtrates is secured by the enlarged propeller channel.

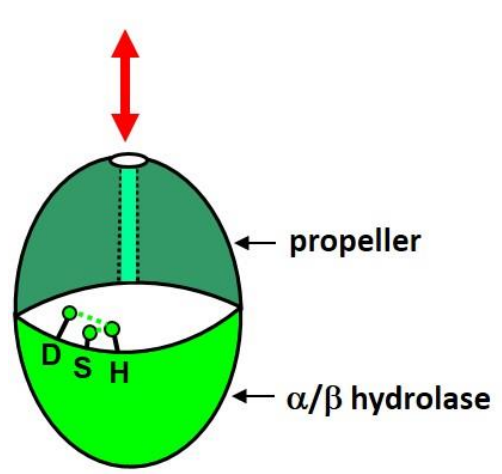

a

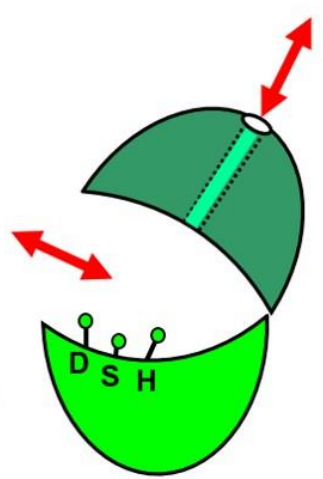

b

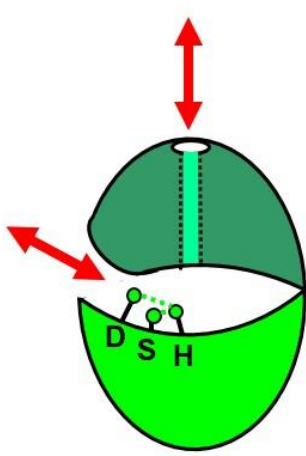

c

Figure 9 Schematic models of oligopeptidase monomers. The hydrolase domain with the catalytic triad is shown in light green, while the propeller domain is colored dark green.

a) The closed form found in structures of both the ligand-free and the ligand-bound states of POPs from various organisms [3, 59, 78, 80], OPB [60, 63], SmAAP/PMH [58] and ApAAP [5, 61, 81, 82]. The catalytic triad is only accessible through the propeller channel. b) Opening of the molecules distort the active site (histidine-carrying loop is displaced), which ensures that the reaction can only take place after the enzyme is "bridged" to the substrate. However, if this molecule is too large (typically a substrate size range does not exceed 30 amino acids in length), it prevents the closure, thus protecting it from hydrolysis. c) Monomers of most of rigid, multimeric strucutres (e.g. DPP4 and $P h$ AAP $[\mathrm{REF}])$ have rigid structure with a side opening

\section{Conclusion}

We can conclude that the functional form of oligopeptidases is determined by several factors. The most significant of these, in our view, are: 1) whether or not the interactions weaving the two domains together play a role in stabilizing the catalytic triad (and thus their absence may provide for its deactivation), and 2) whether the interaction-prone $\beta$-edge of the hydrolase domain is accessible to guide a multimerization process. These cornerstones can be used to estimate yet undetermined structures.

Puromycin hydrolase (PMH) also called Streptomyces morookaensis AAP (SmAAP) was recently characterized as a POP-like enzyme being a member of the "not assigned" subfamily [57]. Its structure was determined and was shown to be monomeric (PDB: 3azo) [58]. In other monomeric structures (POP; PDB 1h2w, OPB; PDB 2xe4) the sticky $\beta$-strands are covered by a long N-terminal extensions thus need no protection. In case of the also monomeric Streptomyces morookaensis AAP, instead of its $\mathrm{N}$-terminal segment, a short C-terminal extension could be responsible for shielding the outer $\beta$-strand (Figure10). In POP (closed PDB: 1h2w, open 5t88) and OPB (closed PDB: 2xe4, open PDB 5n4f) the rigid hydrolase and propeller domains could move apart, creating a spacious entrance for 
substrates like. This could also be the case for PMH, however there is no study yet addressing the dynamic features of this enzyme.

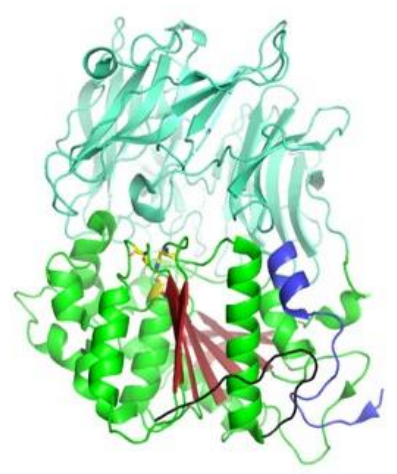

b

Figure 10 The monomeric structure of PMH (SmAAP) (b; PDB: 3azo).The sticky-edge (red) in the hydrolase domain (green), N-terminal extension (blue), catalytic triad (yellow), propeller domain (cyan) and C-terminal extension (black).

Data obtained by investigating the propensity of $\mathbf{S p A A P}$ for quaternary structures by ESI-MS and DLS indicate that the protein is dimeric with a tendency to associate into tetramers, with a suggested arm-exchange mechanism involving the N-terminal helix. [66]. However, its crystal structure containing a dimer formed this way (PDB: 518s) leaves the sticky $\beta$-edge unprotected [2], while the structure of the tetrameric form has not been determined yet. Using the determined structure of the dimeric unit (after removal of the His-tag) formation of a tetrameric assemble can easily be modeled (see Figure 11), resulting in a structure where tetramerization could be responsible for covering the sticky edge and the size-selection of the substrates is secured by the widened propeller channel.

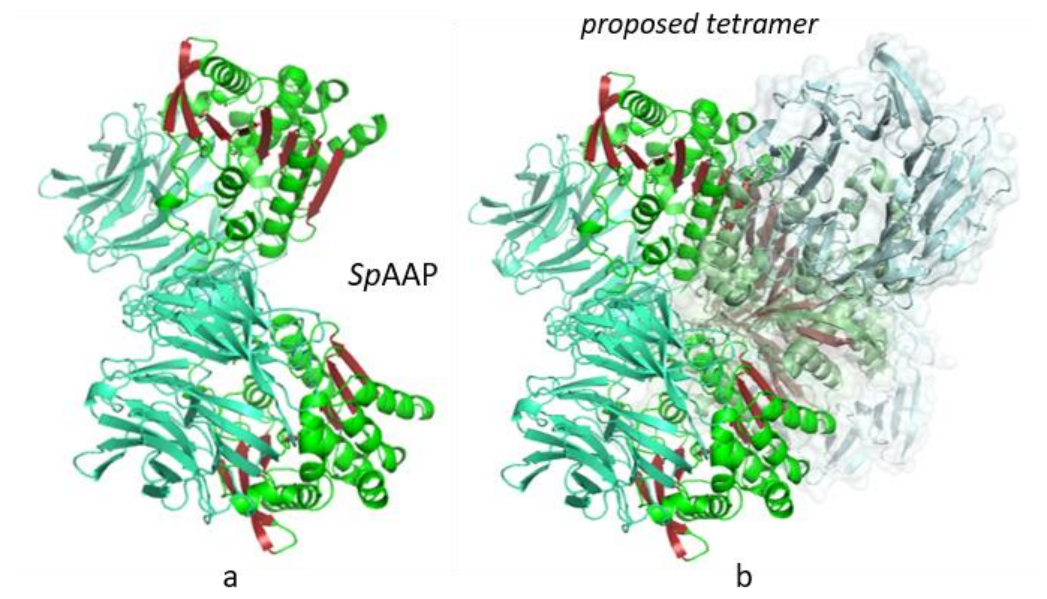

FIGURE 11 The dimer of $\operatorname{SpAAP}$ (PDB: 518s) leaves the sticky-edge unprotected, the proposed structure (drawing by the authors) of a possible tetramerization could cover the aggregation-prone outer $\beta$-strand. 
The structure of the mammalian AAP was also shown to be a tetramer [69]. The purpose of tetramerization could be very likely found between these previous options or a combination of them. Based on sequence fitting and secondary structure prediction, the $\mathrm{N}$-terminal helix structures anchoring the 7-bladed propeller domain to the hydrolase domain is too short and might leave the sticky $\beta$-edge uncovered here, leading to the formation of the tetramer.

The first structure of a carboxypeptidase from Deinococcus radiodurans (S9Cdr) belonging to POP family (and S9C subfamily, in Uniprot database listed as AAP based on sequence identity) was recently reported ([83] PDB: 5yzm). Its structure was shown to be tetrameric, where the $\beta$-edge is covered by a rather large extension of blade 3 of the neighbouring monomer. Domain movement is very likely inhibited by the formation of the tetramer and large side opening is facing inward to the quaternary structure, showing the double gated entry mechanism described in case of PhAAP [71].

\section{Outlook - enzymes lacking the classical two-domain structure}

Some of the structures of acetylcholinesterases, carboxyesterases, lipases of the unassigned group of S9 enzyme family with alpha/beta hydrolase domain but lacking the characteristic propeller domain can be also discussed within the framework proposed by us. A $\beta$-sheet analogous to the two-domain counterparts can be found in their hydrolase core, with possibly aggregation prone outer $\beta$-edges. In monomeric structures this edge is not "sticky" (PDB: $3 \mathrm{k} 2 \mathrm{i}, 4 \mathrm{e} 15,[84,85]$ ) or it is covered by a C-terminal extension usually a $\beta$-strand itself - creating an "aggregation-safe" outer $\beta$-edge (PDB: 1p0i, 1f6w, [86, 87] Figure 12, Table 2) - in line with our expectations.

TABLE2 Summarizing the sequences of the possibly aggregation-prone outer $\beta$-strands (sticky edge) of the $\beta$-sheet (column 3 ) for the unassigned S9 peptidases.

\begin{tabular}{|l|l|l|l|l|l|}
\hline & $\begin{array}{l}\text { PDB } \\
\text { ID }\end{array}$ & $\beta$ - edge forming residues & $\begin{array}{l}\text { predicted } \\
\text { aggregation } \\
\text { propensity a }\end{array}$ & $\begin{array}{l}\text { Functional form of } \\
\text { the enzyme }\end{array}$ & $\begin{array}{l}\text { Formation } \\
\text { Significance } \\
\text { Score(PISA) } \\
\text { b }\end{array}$ \\
\hline $\begin{array}{l}\text { AcCoA } \\
\text { thioesterase } \\
\text { (human) }\end{array}$ & $3 \mathrm{k} 2 \mathrm{i}$ & 134-VWRQSVRAG-142 & Not sticky & monomer & 0.219 \\
\hline $\begin{array}{l}\text { kynurenine } \\
\text { formamidase }\end{array}$ & $4 \mathrm{e} 15$ & 54-TVDHLRYG-61 & Not sticky & monomer & 0.000 \\
\hline butyryl & $1 \mathrm{p} 0 \mathrm{i}$ & 415-NAFFYYFE-422 & 98.29 & monomer & 0.000 \\
\hline
\end{tabular}




\begin{tabular}{|c|c|c|c|c|c|}
\hline $\begin{array}{l}\text { cholinesteras } \\
\text { e (human) }\end{array}$ & & 506-ESTRIMTKL-514 & $\begin{array}{l}\text { not } \\
\text { sticky }\end{array}$ & & \\
\hline $\begin{array}{lr}\text { Bile } & \text { salt } \\
\text { activated } & \text { lipase } \\
\text { (human) } & \end{array}$ & $1 \mathrm{f} 6 \mathrm{w}$ & $\begin{array}{l}\text { 415-NAFFYYFE-422 } \\
\text { 506-ESTRIMTKL-514 }\end{array}$ & $\begin{array}{l}94.94 \\
\text { not sticky }\end{array}$ & monomer & 0.000 \\
\hline Neuroligin 4 & 3be8 & $\begin{array}{l}\text { 466-PTYFYAFY-473 } \\
\text { 576-PRVDRD-580 }\end{array}$ & $\begin{array}{l}94.27 \\
\text { not } \\
\text { sticky }\end{array}$ & dimer & 0.314 \\
\hline $\begin{array}{l}\text { Esterase } \quad \mathrm{D} \\
\text { (human) }\end{array}$ & $3 f \mathrm{fc}$ & 250-VVFRLQE-256 & Not sticky & dimer & 0.000 \\
\hline $\begin{array}{lr}\text { Acyl protein } \\
\text { thioesterase } 1 \\
\text { (human) }\end{array}$ & 5 sym & 197-NVTFKTYEG-205 & 85.49 & dimer $^{*}$ & 0.291 \\
\hline $\begin{array}{l}\text { human } \\
\text { mitochondrial } \\
\text { acyl-CoA } \\
\text { thioesterase } \\
\text { (mAChE) }\end{array}$ & 3hlk & 411-KPQIICYPET-420 & 81.67 & dimer* & 1.000 \\
\hline $\begin{array}{l}\text { Cephalosporin } \mathrm{C} \\
\text { deacetylase }\end{array}$ & $117 \mathrm{a}$ & 287-KKELKVYR-294 & Not sticky & hexamer & 0.000 \\
\hline
\end{tabular}

${ }^{\mathrm{a}}$ The scores for aggregation propensities predicted by WALTZ [75](http://waltz.switchlab.org, accessed November 15, 2018 (column 4), number being higher than 75 indicates that submitted sequence is prone to amyloid-type aggregation.

b PISA (Protein interfaces, surfaces and assemblies' service at the European Bioinformatics Institute, http://www.ebi.ac.uk/pdbe/prot_int/pistart.html, accessed November 15, 2018) [76.] ) calculates interactions of molecular surfaces between submitted structures. The Complex Formation Significance Score for the interaction (CSS ranges from 0 to 1 as interface relevance to complex formation increases. Low CSS implies that the interface is not significant for complex formation and may be solely a result of crystal packing.)

*oligomerization does not cover the sticky edge 


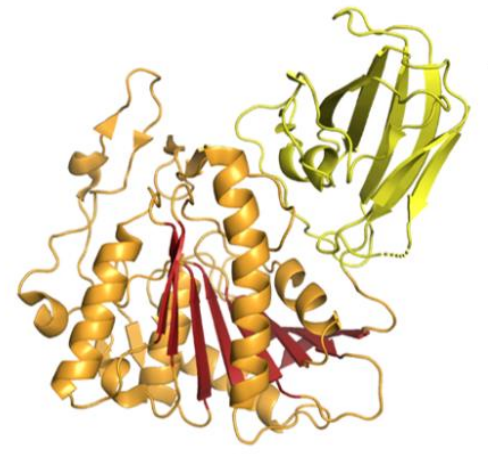

a

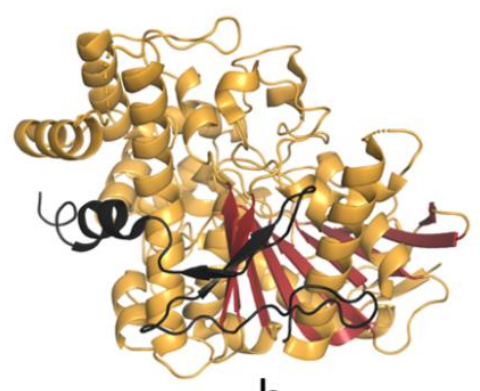

b
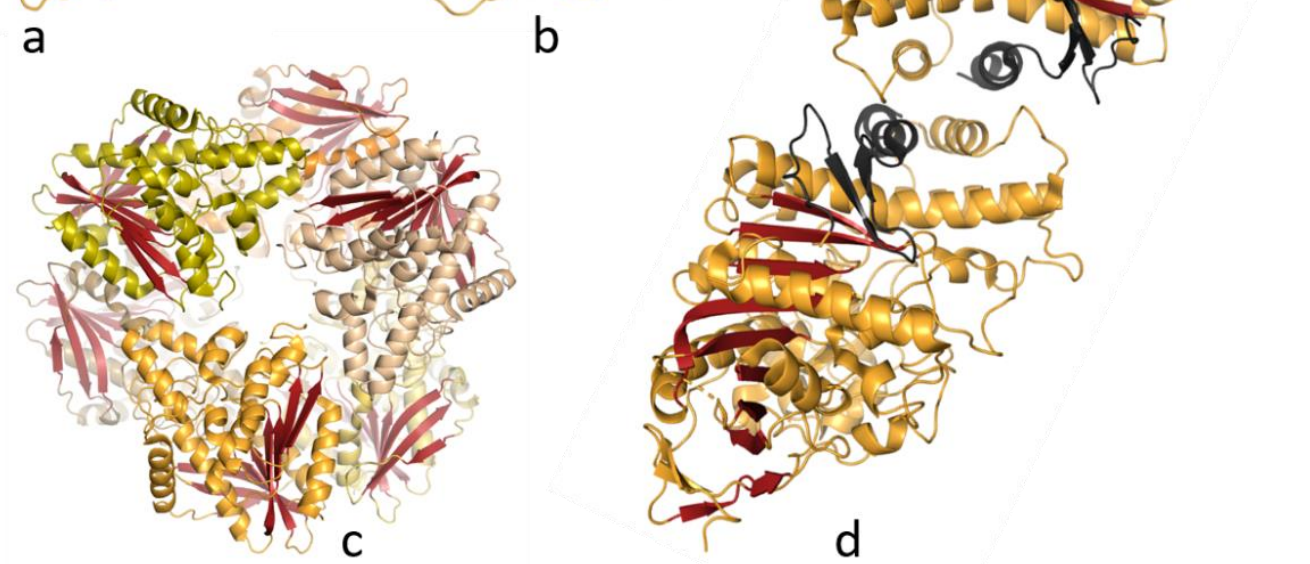

Figure12 Crystal structures of S9 not assigned enzymes. The core of the $\alpha / \beta$-hydrolase domain (orange) is a 8 and a 12 stranded $\beta$-sheet (red). The monomeric structure of a) human acyl-coenzyme A thioesterase 4 (PDB: $3 \mathrm{k} 2 \mathrm{i}$ ) with a $\beta$-sandwich domain (yellow) and b) human butyryl cholinesterase (PDB: 3p0i). c) The hexameric structure of cephalosporin C deacetylase (PDB: 117a) and d) the dimeric structure of neuroligin 4 (PDB: 3be8). The outer $\beta$-edge is not aggregation-prone in acyl-coenzyme

A thioesterase 4 and on cephalosporin $\mathrm{C}$ deacetylase. In structure of butyryl cholinesterase and neuroligin 4 a $\mathrm{C}$-terminal extension (black) is shielding the sticky-edge of the hydrolase.

However, especially in this unassigned subfamily of S9, exceptions to our "rules of thumb" can also be found. For example, oligomerization is not always prompted by the uncovered $\beta$-strands of the central $\beta$-sheet. In the dimeric structures of the extracellular domain of neuroligin 4 (NL4, PDB: 3 be8, [88] ) and human esterase D (hESD, PDB: 3fcx, [89]) as well as in hexamers of cephalosporin C deacetylase (PDB: 117a, [90]), the outer $\beta$-edge is not aggregation-prone, but the structures still oligomerize involving other segments of the hydrolase. The most surprising outliers of our model are some thioesterases (PDB: 5sym, 3hlk, [91,92]), where the $\beta$-edge is predicted to be aggregation prone, but it is not protected by methods discussed in this review. However, the proteins of the unassigned subfamily are topologically significantly different from the A-D subfamilies (hence their unassigned status) thus it is not wholly unexpected that their global architecture, and the rules that govern their build-up will also be different.

Nevertheless, over numerous examples in the structurally more conserved A-D subfamilies of S9 peptidases, interdomain connectedness, $\beta$-structure and the presence or absence of spacious permanent entrances seem to be the most important factors in determining the functional form. The emergence of 
more enzymes using this unique arrangement can be expected, but we feel that their basic functioning can be rationalized by these common principles. 
1. Polgár, L. The prolyl oligopeptidase family. Cell. Mol. Life Sci., 2002, 59(2), 349-62.

2. Brocca, S.; Ferrari, C.; Barbiroli, A.; Pesce, A.; Lotti, M.; Nardini, M., A bacterial acyl aminoacyl peptidase couples flexibility and stability as a result of cold adaptation. FEBS J., 2016, 283(23), 4310-4324.

3. Szeltner, Z.; Rea, D.; Juhász, T.; Renner, V.; Mucsi, Z.; Orosz, G.; Fülöp, V.; Polgár, L. Substrate-dependent competency of the catalytic triad of prolyl oligopeptidase. J. Biol. Chem., 2002, 277(47), 44597-605.

4. Morty, R.E.; Pellé, R.; Vadász, I.; Uzcanga, G.L.; Seeger, W.; Bubis, J. Oligopeptidase B from Trypanosoma evansi. A parasite peptidase that inactivates atrial natriuretic factor in the bloodstream of infected hosts, J. Biol. Chem., 2005, 280(12), 10925-37

5. Harmat, V.; Domokos, K.; Menyhárd, D.K.; Palló A.; Szeltner, Z.; Szamosi, I.; Beke-Somfai, T.; Náray-Szabó, G.; Polgár, L. Structure and catalysis of acylaminoacyl peptidase: closed and open subunits of a dimer oligopeptidase. J. Biol. Chem., 2011, 286(3), 1987-98.

6. Hiramatsu $\mathrm{H}^{1}, \underline{\text { Kyono } \mathrm{K}}$, $\underline{\text { Higashiyama } \mathrm{Y}}$, Fukushima $\mathrm{C}$, $\underline{\text { Shima } \mathrm{H}}$, $\underline{\text { Sugiyama } \mathrm{S}}$, Inaka $\underline{K}, \underline{\text { Yamamoto A }}, \underline{\text { Shimizu } R}$ The structure and function of human dipeptidyl peptidase IV, possessing a unique eight-bladed beta-propeller fold. Biochem Biophys Res Commun. 2003 Mar 21;302(4):849-54.e

7. Rawlings, N.D., Barrett, A.J., Thomas, P.D., Huang, X., Bateman, A. \& Finn, R.D. (2018) The MEROPS database of proteolytic enzymes, their substrates and inhibitors in 2017 and a comparison with peptidases in the PANTHER database. Nucleic Acids Res 46, D624-D632

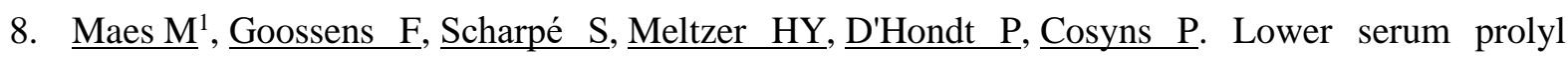
endopeptidase enzyme activity in major depression: further evidence that peptidases play a role in the pathophysiology of depression. Biol Psychiatry. 1994 Apr 15;35(8):545-52.,

9. $\underline{\text { Maes M}}^{1}, \underline{\text { Goossens F }}, \underline{\text { Scharpé S }}, \underline{\text { Calabrese J }}$ Desnyder R, Meltzer HY. Alterations in plasma prolyl endopeptidase activity in depression, mania, and schizophrenia: effects of antidepressants, mood stabilizers, and antipsychotic drugs Psychiatry Res. 1995 Oct 16;58(3):217-25.

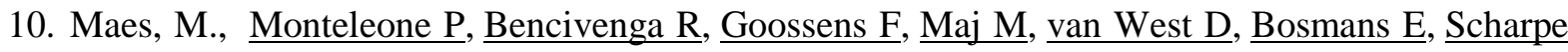
S..., Lower serum activity of prolyl endopeptidase in anorexia and bulimia nervosa. Psychoneuroendocrinology, 2001. 26(1): p. 17-26.

11. Männistö, P.T.; García-Horsman, A.J.;Mechanism of action of prolyl oligopeptidase (PREP) in degenerative brain diseases: has peptidase activity only a modulatory role on the interactions of PREP with proteins? Front. Aging Neurosci., 2017, 9, 27

12. Guardiola, S.; Prades, R; Mendieta, L.; Brouwer, A.J; Streefkerk, J.; Nevola, L; Tarragó, T.; Liskamp, R.M.J.; Giralt, E. Targeted covalent inhibition of prolyl oligopeptidase (POP): discovery of sulfonylfluoride peptidomimetics, Cell. Chem. Biol., 2018, 25(8), 1031-1037.e4 
13. Morty, R.E.; Pellé, R.; Vadász, I.; Uzcanga, G.L.; Seeger, W.; Bubis, J. Oligopeptidase B from Trypanosoma evansi. A parasite peptidase that inactivates atrial natriuretic factor in the bloodstream of infected hosts, J. Biol. Chem., 2005, 280(12), 10925-37

14. Swenerton RK ${ }^{1}$, Zhang S, Sajid M, Medzihradszky KF, Craik CS, Kelly BL, McKerrow JH. The oligopeptidase $\mathrm{B}$ of Leishmania regulates parasite enolase and immune evasion $\mathrm{J}$ Biol Chem. 2011 Jan 7;286(1):429-40

15. Kim, N.H.; Yu, T.; Lee, D.H. The nonglycemic actions of dipeptidyl peptidase-4 inhibitors, Biomed. Res. Int., 2014, 2014, 368703

16. Nathan, D.M. Finding new treatments for diabetes--how many, how fast... how good? N. Engl. J. Med., 2007, 356(5), 437-440

17. Russell, S. Incretin-based therapies for type 2 diabetes mellitus: a review of direct comparisons of efficacy, safety and patient satisfaction. Int. J. Clin. Pharm., 2013, 35(2), 159-172

18. Röhrborn, D., Wronkowitz, N., \& Eckel, J. (2015). DPP4 in Diabetes. Frontiers in immunology, 6, 386.

19. $\underline{\text { Avogaro } \mathrm{A}^{1}}$, Fadini GP The effects of dipeptidyl peptidase-4 inhibition on microvascular diabetes complications Diabetes Care. 2014 Oct;37(10):2884-94

20. $\underline{\text { Aertgeerts } \mathrm{K}^{1}}, \underline{\text { Levin I }}, \underline{\text { Shi LL }}, \underline{\text { Snell GP }}, \underline{\text { Jennings A }}, \underline{\text { Prasad GS }}, \underline{\text { Zhang Y Y }}, \underline{\text { Kraus ML}}, \underline{\text { Salakian }}$ $\underline{\mathrm{S}}, \underline{\text { Sridhar V}}, \underline{\text { Wijnands R}}$, Tennant MG. Structural and kinetic analysis of the substrate specificity of human fibroblast activation protein alpha J Biol Chem. 2005 May 20;280(20):19441-4]

21. Y. Kin, Y. Misumi, Y. IkeharaBiosynthesis and characterization of the brain-specific membrane protein DPPX, a dipeptidyl peptidase IV-related protein J. Biochem. (Tokyo), 129 (2001), pp. 289-295

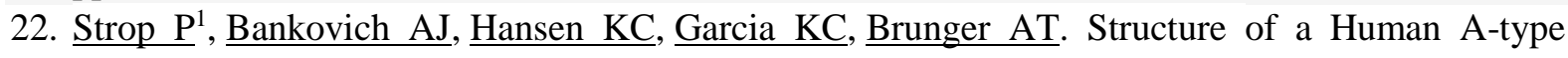
Potassium Channel Interacting Protein DPPX, a Member of the Dipeptidyl Aminopeptidase Family J Mol Biol. 2004 Oct 29;343(4):1055-65

23. $\underline{\operatorname{Ross}}^{1,2}, \underline{\operatorname{Krapp~S}}^{2}, \underline{\text { Augustin }}^{2}, \underline{\text { Kierfersauer }}^{2}, \underline{\text { Arciniega }}^{3}$, Geiss-Friedlander $\mathrm{R}^{4}, \underline{\text { Huber } \mathrm{R}}$ Structures and mechanism of dipeptidyl peptidases 8 and 9, important players in cellular homeostasis and cancer Proc Natl Acad Sci U S A. 2018 Feb 13;115(7):E1437-E1445

24. Bezerra $\quad \mathrm{GA}^{1}$, Dobrovetsky $\quad \mathrm{E}^{2}$, Seitova $\quad \mathrm{A}^{2}$, Fedosyuk $\quad \mathrm{S}^{3}$, Dhe-Paganon $\quad \mathrm{S}^{2}$, Gruber $\quad \mathrm{K}$ Structure of human dipeptidyl peptidase 10 (DPPY): a modulator of neuronal Kv4 channels Sci Rep. 2015 Mar 5;5:8769

25. $\underline{\text { Yamada }} \mathrm{R}^{1}$, $\underline{\text { Ymamoto } \mathrm{K}}$. Recent findings on genes associated with inflammatory disease $\underline{\text { Mutat }}$ Res. 2005 Jun 3;573(1-2):136-51

26. Waumans $\mathrm{Y}^{1}$, Baerts $\mathrm{L}^{1}$, Kehoe $\mathrm{K}^{1}$, Lambeir $\mathrm{AM}^{1}$, De Meester I The Dipeptidyl Peptidase Family, Prolyl Oligopeptidase, and Prolyl Carboxypeptidase in the Immune System and Inflammatory Disease, Including Atherosclerosis Front Immunol. 2015 Aug 7;6:387 
27. Wagner $\mathrm{L}^{1,2}, \underline{\text { Klemann } \mathrm{C}^{3,4}}$, Stephan $\mathrm{M}^{5}$, von Hörsten $\mathrm{S}$ Unravelling the immunological roles of dipeptidyl peptidase 4 (DPP4) activity and/or structure homologue (DASH) proteins Clin Exp Immunol. 2016 Jun;184(3):265-83

28. Banbula, A.; Mak, P.; Bugni, M.; Silberring, J.; Dubin, A.; Nelson, D.; Travis, J.; Potempa, J. Prolyl tripeptidyl peptidase from Porphyromonas gingivalis - A novel enzyme with possible pathological implications for the development of periodontitis. J. Biol. Chem., 1999, 274(14), 9246-9252

29. Xu, Y.; Nakajima, Y.; Ito, K.; Zheng, H.; Oyama, H.; Heiser, U.; Hoffmann, T.; Gartner, U.T.; Demuth, H.U.; Yoshimoto, T. Novel inhibitor for prolyl tripeptidyl aminopeptidase from Porphyromonas gingivalis and details of substrate-recognition mechanism. J. Mol. Biol., 2008, 375(3), 708-719

30. Yamin, R.; Zhao, C.; O'Connor, P.B.; McKee, A.C.; Abraham, C.R. Acyl peptide hydrolase degrades monomeric and oligomeric amyloid-beta peptide. Mol. Neurodegener., 2009, 4, 33

31. Palmieri, G.; Bergamo, P.; Luini, A.; Ruvo, M.; Gogliettino, M.; Langella E.; Saviano M.; Hegde, R.N.; Sandomenico, A.; Rossi, M. Acylpeptide hydrolase inhibition as targeted strategy to induce proteasomal down-regulation. PLoS ONE, 2011, 6(10), e25888

32. Shimizu, K.; Kiuchi, Y.; Ando, K.; Hayakawa, M.; Kikugawa, K. Coordination of oxidized protein hydrolase and the proteasome in the clearance of cytotoxic denatured proteins. Biochem. Biophys. Res. Commun., 2004, 324(1), 140-6

33. Perrier, J.; Durand, A.; Giardina, T.; Puigserver, A. Catabolism of intracellular N-terminal acetylated proteins: involvement of acylpeptide hydrolase and acylase. Biochimie, 2005, 87(8), 673-85

34. Arnesen, T. Towards a Functional Understanding of Protein N-Terminal Acetylation, PLoS Biol., 2011, 9(5), e1001074

35. Forte, G.M.; Pool, M.R.; Stirling, C.J. N-terminal acetylation inhibits protein targeting to the endoplasmic reticulum. PLoS Biol., 2011, 9(5), e1001073

36. Sandomenico, A.; Russo, A.; Palmieri, G.; Bergamo, P.; Gogliettino, P.; Falcigno, L.; Ruvo, M. Small peptide inhibitors of acetyl-peptide hydrolase having an uncommon mechanism of inhibition and a stable bent conformation. J. Med. Chem., 2012, 55(5), 2102-11

37. Fujino, T.; Watanabe, K.; Beppu, M.; Kikugawa, K.; Yasuda, H. Identification of oxidized protein hydrolase of human erythrocytes as acylpeptide hydrolase. Biochim. Biophys. Acta,2000, $1478(1), 102-12$

38. Shimizu, K.; Fujino, T.; Ando, K.; Hayakawa, M.; Yasuda, H.; Kikugawa, K. Overexpression of oxidized protein hydrolase protects COS-7 cells from oxidative stress-induced inhibition of cell growth and survival. Biochem. Biophys. Res. Commun., 2003, 304(4), 766-71 
39. Adibekian, A.; Martin, B.R.; Wang, C.; Hsu, K.L.; Bachovchin, D.A.; Niessen, S.; Hoover, H.; Cravatt, B.F. Click-generated triazole ureas as ultrapotent in vivo-active serine hydrolase inhibitors. Nat. Chem. Biol., 2011, 7(7), 469-78

40. Zeng, Z., Rulten, S.L., Breslin, C., Zlatanou, A., Coulthard, V., and Caldecott, K.W. (2017) Acylpeptide hydrolase is a component of the cellular response to DNA Damage. DNA Repair. 58, $52-61$

41. Erlandsson, R.; Boldog, F.; Persson, B.; Zabarovsky, B.; Allikmets, R.L.; Sümegi, J.; Klein, G.; Jörnvall, $\mathrm{H}$. The gene from the short arm of chromosome 3, at D3F15S2, frequently deleted in renal cell carcinoma, encodes acylpeptide hydrolase. Oncogene, 1991, 6, 1293-5

42. Fage, C.D.; Hegemann, J.D.; Nebel, A.J.; Steinbach, R.M.; Zhu, S.; Linne, U.; Harms, K.; Bange, G.; Marahiel, M.A. Structure and mechanism of the Sphingopyxin I lasso peptide isopeptidase. Angew. Chem. Int. Ed. Engl., 2016, 55(41), 12717-21.

43. Rawlings ND ${ }^{1}$, Barrett AJ. Evolutionary families of peptidases. Biochem J. 1993 Feb 15;290 ( Pt 1):205-18.

44. Liu $\mathrm{F}^{1}$, Zhao $\underline{Z S}^{1}$, ${\underline{\text { Ren } \mathrm{Y}^{1}}}^{\text {, Cheng } \mathrm{G}^{1}}$, ${\underline{\text { Tang } X \mathrm{XF}^{1,2}}}^{\text {Tang } \mathrm{B}^{3,4}}$ Autocatalytic activation of a thermostable glutamyl endopeptidase capable of hydrolyzing proteins at high temperatures Appl Microbiol Biotechnol. 2016 Dec;100(24):10429-10441

45. Ohara-Nemoto $\mathrm{Y}^{1}$, Ikeda Y, Kobayashi M, Sasaki M, Tajika S, Kimura S. Characterization and molecular cloning of a glutamyl endopeptidase from Staphylococcus epidermidis Microb Pathog. 2002 Jul;33(1):33-41.

46. Calander AM, Dubin G, Potempa J, Tarkowski A. Staphylococcus aureus infection triggers production of neutralizing, V8 protease-specific antibodies. FEMS Immunol Med Microbiol. 2008 Mar;52(2):267-72.

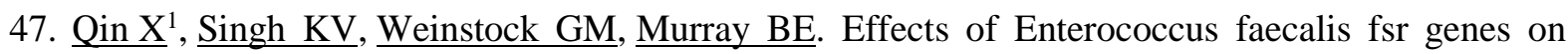
production of gelatinase and a serine protease and virulence. Infect Immun. 2000 May;68(5):2579-86

48. Lee CW, Yang IS. Cutaneous calcinosis in erythromelanosis follicularis faciei et colli. Clin Exp Dermatol. 1987 Jan;12(1):31-2.

49. O'Toole PW, Foster TJ. Nucleotide sequence of the epidermolytic toxin A gene of Staphylococcus aureus. J Bacteriol. 1987 Sep;169(9):3910-5.

50. Dancer SJ ${ }^{1}$, Garratt R, Saldanha J, Jhoti H, Evans R. The epidermolytic toxins are serine proteases. FEBS Lett. 1990 Jul 30;268(1):129-32.

51. Bukowski $\mathrm{M}^{1}$, Wladyka B,$\underline{\text { Dubin G. Exfoliative toxins of Staphylococcus aureus. Toxins }}$ (Basel). 2010 May;2(5):1148-65.

52. Griffen, A.L.; Becker, M.R.; Lyons, S.R.; Moeschberger, M.L.; Leys, E.J. Prevalence of Porphyromonas gingivalis and periodontal health status. J. Clin. Microbiol., 1998, 36(11), 32393242. 
53. Iwai, T.; Inoue, Y.; Umeda, M.; Huang, Y.; Kurihara, N.; Koike, M.; Ishikawa, I. Oral bacteria in the occluded arteries of patients with Buerger disease. J. Vasc. Surg., 2005, 42(1), 107-115

54. Kshirsagar, A.V.; Offenbacher, S.; Moss, K.L.; Barros, S.P.; Beck, J.D. Antibodies to periodontal organisms are associated with decreased kidney function. The dental atherosclerosis risk in communities study. Blood Purif., 2007, 25(1), 125-132

55. Detert, J.; Pischon, N.; Burmester, G.R.; and Buttgereit, F. The association between rheumatoid arthritis and periodontal disease. Arthritis Res. Ther., 2010, 12(5), 218

56. Nemoto, T.,K.; Ohara-Nemoto, Y.; Bezerra, G.A.; Shimoyama, Y.; Kimura, S. A Porphyromonas gingivalis periplasmic novel exopeptidase, acylpeptidyl oligopeptidase, releases $\mathrm{N}$-acylated diand tripeptides from oligopeptides. J. Biol. Chem., 2016, 291(11), 5913-5925

57. Nishimura, M.; Ikeda, K.; Sugiyama, M. Molecular cloning and characterization of gene encoding novel puromycin-inactivating enzyme from blasticidin S-producing Streptomyces morookaensis. J. Biosci. Bioeng., 2006, 101(1), 63-69,

58. Matoba, Y.; Nakayama, A.; Oda, K.; Noda, M.; Kumagai, M.; Nishimura, M.; Sugiyama, M. Structural evidence that puromycin hydrolase is a new type of aminopeptidase with a prolyl oligopeptidase family fold. Proteins, 2011, 79(10), 2999-3005

59. Fülöp, V.; Böcskei, Z.; Polgár, L. Prolyl oligopeptidase: an unusual beta-propeller domain regulates proteolysis. Cell, 1998, 94(2), 161-70.

60. McLuskey, K.; Paterson, N.G.; Bland, N.D.; Isaacs, N.W.; Mottram, J.C. Crystal structure of Leishmania major oligopeptidase $\mathrm{B}$ gives insight into the enzymatic properties of a trypanosomatid virulence factor. J. Biol. Chem., 2010, 285(50), 39249-59

61. Bartlam, M.; Wang, G.; Yang, H.; Gao, R.; Zhao, X.; Xie, G.; Cao, S.; Feng, Y.; Rao, Z. Crystal structure of an acylpeptide hydrolase/esterase from Aeropyrum pernix K1. Structure, 2004, 12(8), 1481-8.

62. Rasmussen, H.B.; Branner, H.B.; Wiberg, F.C.; Wagtmann, N. Crystal structure of human dipeptidyl peptidase IV/CD26 in complex with a substrate analog. Nat. Struct. Biol., 2003, 10(1), $19-25$.

63. Canning, P.; Rea, D.; Morty, R.E.; Fülöp, V. Crystal structures of Trypanosoma brucei oligopeptidase B broaden the paradigm of catalytic regulation in prolyl oligopeptidase family enzymes. PLoS One, 2013, 8(11), e79349

64. Motta, F.N.; Bastos, I.M.; Faudry, E.; Ebel, C.; Lima, M.M.; Neves, D.; Ragno, M.; Barbosa, J.A.; de Freitas, S.M.; Santana, J.M. The Trypanosoma cruzi virulence factor oligopeptidase B (OPBTc) assembles into an active and stable dimer. PLoS One, 2012, 7(1), e30431.

65. Fukumoto, J.; Ismail, N.I.; Kubo, M.; Kinoshita, K.; Inoue, M.; Yuasa, K., Nishimoto, M.; Matsuki, H.; Tsuji, A. Possible role of inter-domain salt bridges in oligopeptidase B from Trypanosoma brucei: critical role of Glu172 of non-catalytic b-propeller domain in catalytic activity and Glu490 of catalytic domain in stability of OPB, J. Biochem., 2013, 154(5), 465-473. 
66. Papaleo, E.; Paravicini, F.; Grandori, R.; De Gioia, L.; Brocca, S. Structural investigation of the cold-adapted acylaminoacyl peptidase from Sporosarcina psychrophila by atomistic simulations and biophysical methods. Biochim. Biophys. Acta, 2014, 1844(12), 2203-2213

67. Szeltner, Z.; Kiss, A.L.; Domokos, K.; Harmat, V.; Náray-Szabó, G.; Polgár, L. Characterization of a novel acylaminoacyl peptidase with hexameric structure and endopeptidase activity. Biochim. Biophys. Acta, 2009, 1794(8), 1204-1210

68. Mitta, M.; Asada, K.; Uchimura, Y.; Kimizuka, F.; Kato, I.; Sakiyama, F.; Tsunasawa, S. The primary structure of porcine liver acylamino acid-releasing enzyme deduced from cDNA sequences. J Biochem, 1989, 106(4), 548-51

69. Wright, H.; Kiss, A.L.; Szeltner, Z.; Polgár, L.; Fülöp, V. Crystallization and preliminary crystallographic analysis of porcine acylaminoacyl peptidase. Acta Crystallogr. Sect. F Struct. Biol. Cryst. Commun., 2005, 61(10):942-944.

70. Fuxreiter, M., Magyar, C., Juhász, T., Szeltner, Z., Polgár, L., Simon, I.; Flexibility of prolyl oligopeptidase: molecular dynamics and molecular framework analysis of the potential substrate pathways. Proteins, 2005, 60(3), 504-12

71. Menyhárd, D.K.; Kiss-Szemán, A.; Tichy-Rács, É.; Hornung, B.; Rádi, K.; Szeltner, Z.; Domokos, K.; Szamosi, I.; Náray-Szabó, G.; Polgár, L.; Harmat, V. A self-compartmentalizing hexamer serine protease from Pyrococcus horikoshii: substrate selection achieved through multimerization. J. Biol. Chem., 2013, 288(24), 17884-94.

72. Kaszuba, K.; Rog. T.; St Pierre. J.F.; Mannisto. P.T.; Karttunen. M.; Bunker, A. Molecular dynamics study of prolyl oligopeptidase with inhibitor in binding cavity. SAR QSAR Environ. Res., 2009, 20(7-8), 595-609.

73. Menyhárd, D.K.; Orgován, Z.; Szeltner, Z.; Szamosi, I.; Harmat, V. Catalytically distinct states captured in a crystal lattice: the substrate-bound and scavenger states of acylaminoacyl peptidase and their implications for functionality. Acta Crystallogr. D Biol. Crystallogr., 2015, 71(3), 46172.

74. Richardson, J.S.; Richardson, D.C. Natural beta-sheet proteins use negative design to avoid edgeto-edge aggregation. Proc. Natl. Acad. Sci. U S A, 2002, 99(5), 2754-9

75. Maurer-Stroh, S.; Debulpaep, M.; Kuemmerer, N.; de la Paz Lopez, M.; Martins, I.C.; Reumers, J.; Morris, K.L.; Copland, A.; Serpell, L.; Serrano, L.; Schymkowitz, J.W.; Rousseau, F. Exploring the sequence determinants of amyloid structure using position-specific scoring matrices. Nat. Methods, 2010, 7, 237-242

76. Krissinel, E.; Henrick, K. Inference of macromolecular assemblies from crystalline state. J. Mol. Biol., 2007, 372(3), 774-797.]

77. Szeltner, Z.; Rea, D.; Juhász, T.; Renner, V.; Fülöp, V.; Polgár, L. Concerted structural changes in the peptidase and the propeller domains of prolyl oligopeptidase are required for substrate binding. J. Mol. Biol., 2004, 340, 627-637. 
78. Shan, L.; Mathews, I.I.; Khosla, C. Structural and mechanistic analysis of two prolyl endopeptidases: role of interdomain dynamics in catalysis and specificity. Proc. Natl. Acad. Sci. U S A, 2005, 102(10), 3599-604.

79. Czekster, C.M.; Ludewig, H.; McMahon, S.A.; Naismith, J.H., Characterization of a dual function macrocyclase enables design and use of efficient macrocyclization substrates. Nat. Commun., 2017, 8, 1045.

80. Li, M.; Chen, C.; Davies, D.R.; Chiu, T.K. Induced-fit mechanism for prolyl endopeptidase. J. Biol. Chem., 2010, 285(28), 21487-95

81. Kiss, A.L.; Hornung, B.; Rádi, K.; Gengeliczki, Z.; Sztáray, B.; Juhász, T.; Szeltner, Z.; Harmat, V.; Polgár, L. The acylaminoacyl peptidase from Aeropyrum pernix K1 thought to be an exopeptidase displays endopeptidase activity. J. Mol. Biol., 2007, 368(2), 509-20

82. Kiss, A.L.; Palló, A.; Náray-Szabó, G.; Harmat, V.; Polgár, L. Structural and kinetic contributions of the oxyanion binding site to the catalytic activity of acylaminoacyl peptidase. $J$. Struct. Biol., 2008, 162(2), 312-23.

83. Yadav $\mathrm{P}^{1}$, Goyal $\mathrm{VD}^{1}$, Gaur $\quad \mathrm{NK}^{1}$, Kumar $\quad \mathrm{A}^{1}$, Gokhale $\quad \mathrm{SM}^{2}$, ${\underline{\text { Jamdar }} \quad \mathrm{SN}^{1}}^{1}$, Makde $\quad \mathrm{RD}^{3}$ Carboxypeptidase in prolyl oligopeptidase family: Unique enzyme activation and substratescreening mechanisms J Biol Chem. 2018 Nov 8. pii: jbc.RA118.004254

84. Siponen, M.I., Moche, M., Arrowsmith, C.H., Berglund, H., Bountra, C., Collins, R., Edwards, A.M., Flodin, ～S., Flores, ～A., Graslund, S., Hammarstrom, ～M., Johansson, ～A., Johansson, I., Kallas, A., Karlberg, T., Kraulis, P., Kotenyova, T., Kotzsch, A., Markova, N., Nielsen, T.K., Nordlund, P., Nyman, T., Persson, C., Roos, A.K., Schutz, P., Svensson, L., Thorsell, A.G., Tresaugues, L., Van Den Berg, S., Wahlberg, E., Weigelt, J., Welin, M., Wisniewska, M., Schuler, H., Structural Genomics Consortium (SGC) DOI: $10.2210 / \mathrm{pdb} 3 \mathrm{~K} 2 \mathrm{I} / \mathrm{pdb}$ to be published

85. $\underline{\text { Han }} \mathrm{Q}^{1}, \underline{\text { Robinson } \mathrm{H}}, \underline{\mathrm{Li} \mathrm{J}}$. Biochemical identification and crystal structure of kynurenine formamidase from Drosophila melanogasterBiochem J. 2012 Sep 1;446(2):253-60

86. Nicolet $\mathrm{Y}^{1}$, Lockridge O, Masson P, Fontecilla-Camps JC, Nachon F Crystal structure of human butyrylcholinesterase and of its complexes with substrate and products J Biol Chem. 2003 Oct 17;278(42):41141-7.

87. Terzyan $\mathrm{S}^{1}$, Wang CS, Downs D, Hunter B, Zhang XC Crystal structure of the catalytic domain of human bile salt activated lipase Protein Sci. 2000 Sep;9(9):1783-90.

88. Fabrichny $\mathbf{I P}^{1}$, Leone $\mathbf{P}$, Sulzenbacher G, Comoletti D, Miller MT, Taylor P, Bourne Y, Marchot P. Structural analysis of the synaptic protein neuroligin and its beta-neurexin complex: determinants for folding and cell adhesion Neuron. 2007 Dec 20;56(6):979-91.

89. Wu $\mathbf{D}^{1}$, Li Y, Song G, Zhang D, Shaw N, Liu ZJ. Crystal structure of human esterase D: a potential genetic marker of retinoblastoma FASEB J. 2009 May;23(5):1441-6 
90. Zhang, R., Koroleva, O., Collert, F., Joachimiak, A. 1.5A crystal structure of the Cephalosporin C deacetylase To be published. DOI: 10.2210/pdb1L7A/pdb)

91. Won $\mathrm{SJ}^{1}$, Davda $\quad \mathrm{D}^{1}$, Labby $\mathrm{KJ}^{1}$, Hwang $\mathrm{SY}^{1}$, Pricer $\quad \mathrm{R}^{1}$, Majmudar $\mathrm{JD}^{1}, \underline{\text { Armacost }}$ $\underline{\mathrm{KA}}^{1}, \underline{\text { Rodriguez } \quad \mathrm{LA}^{1}}, \underline{\text { Rodriguez } \quad \mathrm{CL}^{1}}$, $\underline{\mathrm{ES}}^{1}, \underline{\text { Meagher } \mathrm{JL}^{1}}$, ${\underline{\text { Brooks CL } 3 \mathrm{rd}^{1}}}^{1}, \underline{\text { Stuckey JA}}^{1}, \underline{\text { Martin BR }}^{1}$ Molecular Mechanism for IsoformSelective Inhibition of Acyl Protein Thioesterases 1 and 2 (APT1 and APT2) ACS Chem Biol. 2016 Dec 16;11(12):3374-3382

92. Mandel $\mathrm{CR}^{1}$, Tweel B , Tong L Crystal structure of human mitochondrial acyl-CoA thioesterase (ACOT2 Biochem Biophys Res Commun. 2009 Aug 7;385(4):630-3 
Acknowledgements: The research within projects No. VEKOP-2.3.2-16-2017-00014 and VEKOP-2.3.315-2017-00018were supported by the European Union and the State of Hungary, co-financed by the European Regional Development Fund. This work was supported by the Hungarian Scientific Research Fund OTKA K116305 and the MedInProt program of the Hungarian Academy of Sciences. 
